\title{
Seasonal Dynamics of Bird Differences and Numbers in the South- Western Kizilkum Reservoirs
}

\author{
Turayev Mukhtor Murodovich ${ }^{1 *}$, Sharifova Shokhsanam Shokir Qizi ${ }^{1}$
}

${ }^{1}$ Department of Biology Bukhara State University, Bukhara, Uzbekistan

\section{*Corresponding Author}

Turayev Mukhtor Murodovich

\section{Article History}

Received: 27.02.2021

Accepted: 10.03.2021

Published: 19.04.2021

Abstract: The article analyzes the species composition, number and ecological factors influencing the redistribution of birds in water bodies in different types of water basins of South-West Kizilkum and the seasonal dynamics of birds.

Keywords: desert zone, migrant, environmental factors, biocenosis, adaptation.

\section{INTRODUCTION}

Since the second half of the last century, the expansion of irrigated arable land in the country has led to an increase in groundwater levels and salinization around these fields. As a result, measures have been taken to reduce the groundwater level by digging ditches around agricultural fields, which has led to the formation of a number of artificial ashes in the country. The impact of these changes on nature is so multifaceted that each change is followed by the formation of biocenoses that are not previously specific to the region.

We know that the largest irrigation system in the country is formed by the waters of the Amudarya and Syrdarya. The deltas (spreads) formed in the lower reaches of this river, the islands between them, the reeds and tugai along the shores of the Aral Sea, are the favorite habitats of the species that make up the ornithofauna of the region.

However, in the south-eastern and central regions of the country, especially in Bukhara, Navoi, Khorezm and Kashkadarya regions, located at a depth of sea level, since the 1950s, Dengizkul, Zamobobo, Ayak-Ogitma, Karakir lakes, Shurkul, Kuyimozor, Tudakul reservoirs. With the release of such canals as Bukhara-1, Amu Bukhara-2, Amu Karakul, Amu Karshi, around these canals Zikri, Khadija, Devxona, Khojamsayod, Sechankul, Achchikkul, Alan slaves, as well as dozens of fish ponds associated with the formation, life, water environment and leading to the redistribution of waterfowl throughout the country. The results of our observations in 2000-2020 in Karakir, Zamonbobo, Dengizkul.

Zikri, Khadicha, Qumsultan, Ayak Ogitma lakes, Kagan and Bukhara fish ponds in Bukhara region, Tudakul and Kuyimozor reservoirs in Navoi region will be analyzed.

\section{Materials ANd Methods}

During our observations, information on species diversity, distribution, bioecological features of water and underwater birds registered in water basins is described. In this case, the analysis of species diversity and distribution ecology was based on the methods of Kashkarov [1] and Novikov [2], the current state of seasonal and biotopic stagnation of bird numbers using the methods of 2017 Lanovenko, Felatov, Felatova.

\section{Outcome analysis}

Since the second half of the twentieth century, due to the economic activities of mankind, the standard of living of mankind has improved through the application of scientific and technical achievements in various sectors of the economy, and the weight of changes in the environment is deepening.

Copyright (C) 2021 The Author(s): This is an open-access article distributed under the terms of the Creative Commons Attribution 4.0 International License (CC BY-NC 4.0) which permits unrestricted use, distribution, and reproduction in any medium for non-commercial use provided the original author and source are credited. 
These data are based on our observations of the Zarafshan downstream during 2000-2020. Our observations were made in natural and abandoned lakes, reservoirs and fish ponds in Bukhara and Navoi regions.

Depending on the territorial conditions specific to the desert zone, the water basins will serve as a resting place for migrant and sedimentary birds and waterfowl in all seasons of the year, a feeding center for migrant migrants, and a place of migration for local migrants, the nesting of a number of migratory species during the breeding season is also a convenient place for the chicks to grow up.

However, the species composition and number of birds in the aquifer vary throughout the seasons. It should be noted that this picture depends on the abundance of nutrients in the waters, the degree of influence of biotic and abiotic factors, the strength of anthropogenic transformation.

Spring migration of birds in the wetlands begins in the first ten days of February (5.02.2001, 7.02.2011, 6.02.2013) and lasts until March and April in the years when winter is warm. In the years of prolonged winter, especially in the years when a sharp drop in temperature is observed from February, the flight times of migrants are extended to the last days of February (21.02.2007, 19.02.2008) [4. P.21-24].

During our observations, 83 species of birds belonging to 9 genera were found in the lake system in the spring. During the spring season, birds $(40.5 \%)$ recorded in water basins were encountered in March, (40.0\%) in April, and $(19.5 \%)$ in May.

Of the 18 species of ducks recorded in the watersheds, $96 \%$ were species that fly through the area. The active movements of the birds are most pronounced in the first half of March [5.14-55 p.].

Among the species mentioned are anas crecca and Anas querquedula, diamond duck- Netta rufina and crocodiles- Anas platyrhynchos. They have accumulated in almost all lakes in the system, especially in the algae-rich Khadija and Zikri, Karakir, Zamonbobo lakes. By the last days of spring, the number of ducks in the lakes is drastically reduced due to flying squirrels.

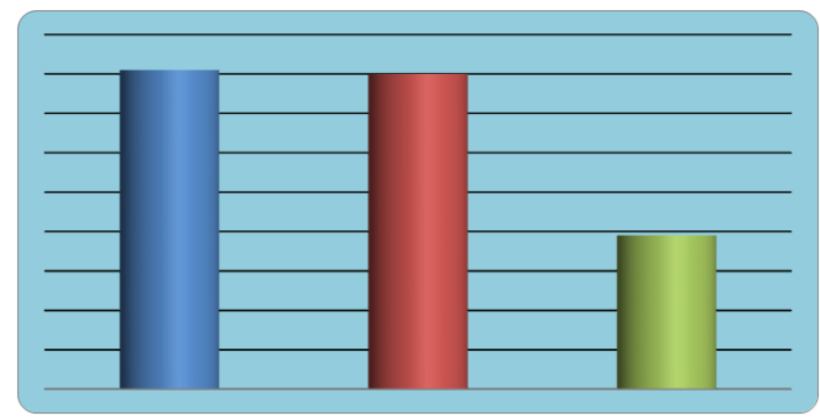

Diagram-1: Dynamics of bird activity in spring season

Among the flying species, a large number of species such as Mergus sniper, bad moth - Mergellus albellus, fluffy black and Chinese duck - Bucephala clangula were recorded in the first days of March in small numbers. The main part of these ducks is collected from the first decade of March in the lakes of Dengizkul, Ogitma, Karakir and Zamonbobo lakes, which have large open areas. Before the migration of migratory species is completed, wild ducks Anas platyrhynchos, diamond ducks - Netta rufina, white-eyed ducks - Aythya nyroca and gray geese - Anser anser from migratory species involved in nesting are observed throughout the region to build nests. In doing so, they mainly choose the reeds of high-grass,

Karakir, Zikri, Zamonbobo, Khadija lakes and small water basins. These movements will be visible from midMarch to mid-April.

Another species that stands out in large numbers in water bodies is the Fulica atra. Representatives of this species from 1000 to 20,000 galas in the pond southwest of the Khadija, Zikri, Karakir, Zamonbobo and Tudakul reservoirs, which are rich in algae of the mentioned aquifers, and select reeds in the aquifers during reproduction [5.14-65 p.].

In the lake system, silverfish, lake fishermen, and slender-nosed fishermen are distinguished by their wider distribution than the rest of the family. Our observations revealed that $21.6 \%$ of the total number of fishing birds was lake fishermen - Larus ridibundus, 7.7\% - silver fishermen - Larus argentatus and 54.2\% - small-nosed fishermen - Larus 
genei. Larus ichthyaetus, a small number of black-headed fishermen who have wintered in water bodies, also accounts for $0.1 \%$ of this figure. Among the locusts are small locusts- Sterna albifrons and river locusts- Sterna hirund they start flying from the second decade of April. They are distinguished by a large number of locusts, which accounted for $2.6 \%$ and $4.6 \%$ of the total number of birds [3.p. 133b, 8.283-290].

While fishing birds are observed to gather along the shores and islands of large lakes in the early days of the season, they begin to occupy nesting areas from the last days of March. Birds are distributed throughout lakes and ponds during nesting. Silver fishermen Larus argentatus chose Zikri, Zamonbobo lakes, Tudakul reservoir and Khadija Lake as the main nesting center. The small-nosed fisherman Larus genei builds nests in small groups on the islands of the Kuyimozor Reservoir and Lake Khadija [3.p.133, 5. p.45]. The bird family, which represented the largest number of species of ornithofauna in the lake system during the season, is a group of migratory birds, and 25 species of them were recorded during our observations. They account for $18.0 \%$ of the total number of birds observed. Of this amount, $23.0 \%$ was registered in March, 39.9\% in April and 37.1 \% in May. During the spring migration, the birds are mainly distributed in Lake Khadicha, in the north-western part of Dengizkol, in the ponds of Kagan and Bukhara fisheries, as well as along the northern shores of Todakol [1 .p.97-99,9.206-208], Among the most numerous species of migrants are lake mudTringa stagnatilis sparrow mosquito -Calidris minuta, round-nosed plavunchik-Phalaropus lobatus, big mud-Tringa nebularia, squirrel mud-Actit hypoleucos, turukhtan-Calomachid temugnax, Philoughus limuginax, Philomachus pugnax, small veretennik- Limosa lapponica, erysipelas-Tringa totanus, as well as large erysipelas and watercress Vanellochettusia leucura, which build nests in the area, are recorded in numbers of 250-3500 on some counting days. In the last days of the season, this number has been gradually declining due to the number of flying representatives.

Among the species mentioned during our observations, $7.9 \%$ of the total number of hydrophilic birds Pelecanus crispus and pink peacocks - Pelecanus onocrotalus occupy the islands in the southern and northern parts of Lake Dengizkul, Karakir and Lake Zikri for rest and gathering. At this time, their galas can count from 150 to 300 monkeys. Although their main feeding areas are Zikri and Khadija and Karakir lakes, they can be observed in all water bodies during the last month of spring. Of the total number of pelicans observed during the season, $64.2 \%$ occur in March, $21.0 \%$ in April, and $14.8 \%$ in May.

There are 7 species of rhinos in the lake system, which account for $5.1 \%$ of the total among waterfowl and underwater birds. The number of Ardea cinerea is $37.8 \%$ of the total number of family members, the number of large white sheep is Casmerodius albus is $45.4 \%$, the number of small white sheep is $23.5 \%$ is the number of Egretta garzetta, and the number of straw cows is Ardea purpurea. 9.6\%. Among these species, at a time when the number of blue-tailed deer was stagnant during the season, we observed that the number of large and small white-tailed deer varied in opposite directions, ie, in large white-tailed deer $-89.1 \%$ of the total number of Casmerodius albus in March, 8 , While $6 \%$ were recorded in April and $2.3 \%$ in May, we witnessed an increase in the number of small white squirrels - Egretta garzetta - from $15.4 \%, 65.2 \%$, and $19.4 \%$, respectively, since the second half of March. A similar pattern was observed in the increase in the increase in the number of Ardea purpureas.

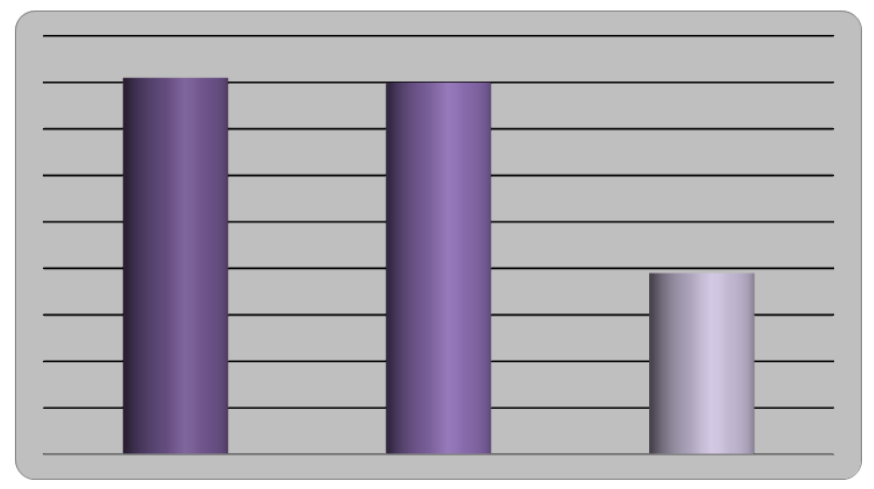

Diagram-2

The essence of these two landscapes is explained by the spring migration movements and the concentration of species representatives involved in nest building. That is, while these waterfowl are seasonal recreation centers for large white rhinos, small white rhinos participate in the construction of a large number of nests in the reeds of the observed waterfowl [2.p. 101-104., 12.71-74]. A distinctive feature of desert zone waters is that the area of forests and thick reeds around these waters is not large. This landscape has led to certain changes in the etiology of birds in recent years. In particular, since 2001, the first swans Nycticorax nycticorax, since 2008-small white crows - Egretta garzetta, and since 2013 - Egyptian crows - Bubulcus ibis ibis, and today tens of km from the waters. Romitan, Alat, in the viola, that manure crows in the woods of distant cities formed a mixed colony with the Corvus gilegus. 

12.71-74].

It should be noted that we noted in the parks in the center of Karakol, Jondor, Kagan and Bukhara [5. $79 \mathrm{~b}$

The results of our observations show that the number and species composition of ornithofauna in water basins differ not only in the nature of the formation of water bodies, but also in the type of water bodies themselves, depending on the ecological status of the water basin itself,depending on the ecological status of the water basin, species composition and number of birds.

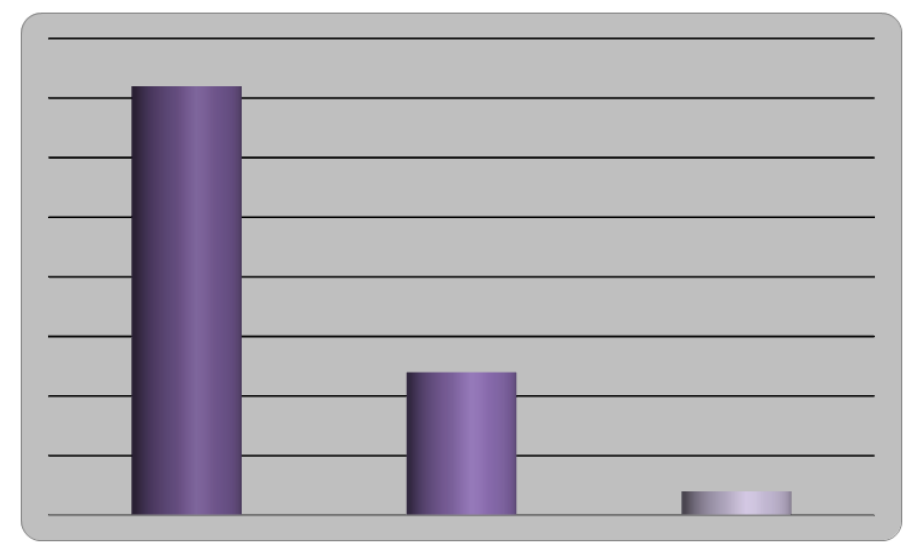

Diagram-3

The results of our observations show that the amount and species composition of ornithofauna in the waters during the season is free from various biotic and abiotic influences of the watershed, as well as lakes such as Dengizkul, Karakir, Zaminbobo, Zikri and Tudakul, Kuyimozor reservoirs, Kagan fishery, serve as the main concentration centers.

Also, $72 \%$ of the birds registered during the season in the watershed area were recorded in the lake area, $24 \%$ in reservoirs, $4 \%$ in fisheries. $32 \%$ of the birds recorded in the lakes were registered in Dengizkol, $26 \%$ - in Karakir and $20 \%$ - in the territory of Ayak-Ogitma, Khadija, Zikri, Zamonbobo lakes.

Ornithological condition in autumn. The ornithological situation in the autumn in the waters is characterized by very rapid and abrupt changes. The basis of this feature is related to the autumn migration movements of migratory species. In this regard, we can observe that the species composition, number, concentration centers, and diversity of birds in lakes change frequently during the season.

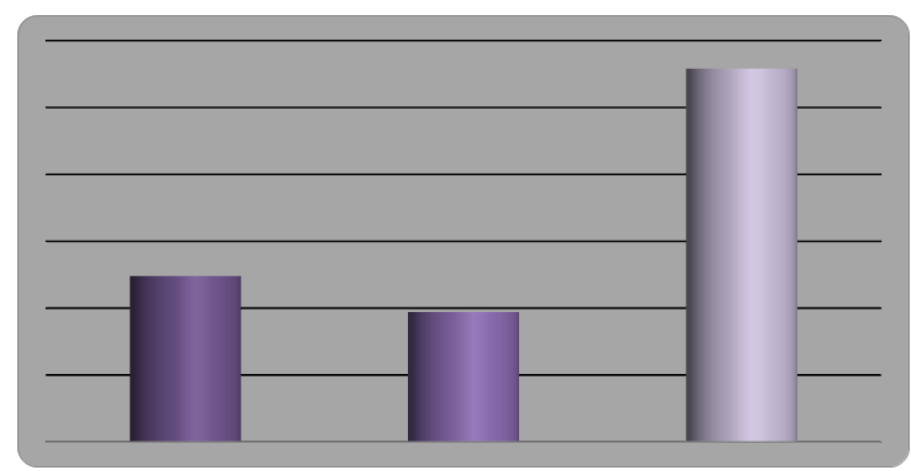

Diagram-4: Autumn dynamics of birds in the lakes

During the season, 55 bird species were recorded in the lake area, of which $24.8 \%$ were recorded in September, $19.4 \%$ in October, and $55.8 \%$ in November. We observed that the species diversity was 34,31 , and 29 , respectively.

If we look at the monthly changes in ornithofauna, $29.7 \%$ of the birds recorded in September - ducks members of the family Anatidae, 24.7\% - fishing birds - Laridae,13.7\% - mud birds- Charadriiformes, 17.9\%-crowsRepresentatives of the Ardeidae family and the rest were Phalacrocoracidae, Threskiornithidae, and Pelecanidae. The uneven distribution of birds along the watersheds occurs as a result of a sharp drop in the water level in the watersheds in the area. This is particularly the case in the Khadija, Zikri and Zamonbobo lakes, the Kagan fishing ponds, and the Tudakul Reservoir, one of the concentration centers for many migratory birds. 
Since October, a number of species of waterfowl and aquatic birds such as Charadrius alexandrinus, waterfowl- Rallus aquaticus, large eagle- Himantopus himantopus, mudfish- Gallinago gallinago, border- Hydroprogne caspia have completed the autumn migration period in the Anpan region, from this month anser, gray crane- Grus grus, white stork- Ciconia siconia and black stork- Ciconia nigra.

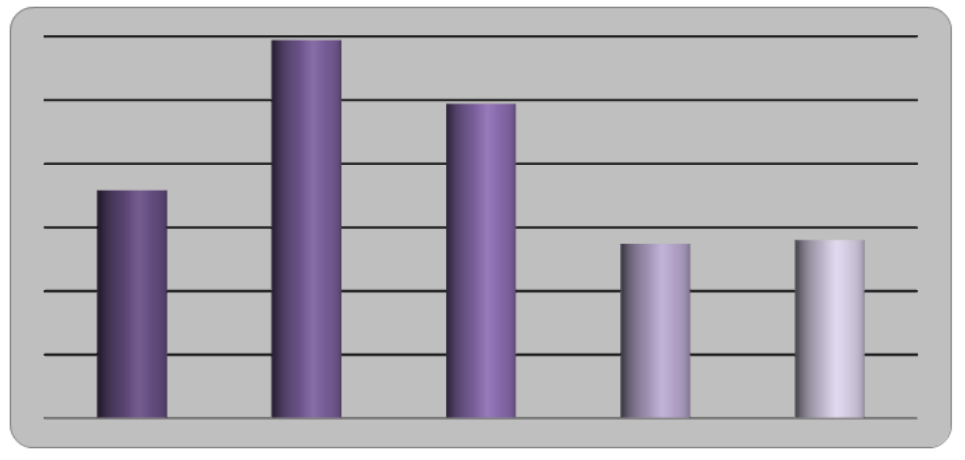

Diagram-5: Dynamics of the number of birds in the lakes in September

The swan-Vanellus vanellus, targok- like Chettusia gregaria Phalacrocorax rygmaeus, Phalacrocorax carbo, Botaurus stellaris, Casmerodius albus, Ardea purpurea, chryakva, kryakva The number of birds is increasing due to species such as crecca, thin-billed fisherman. In November, $39.1 \%$ of the total number of registered birds, ducks Anatidae, 26.7\%, cattle - Phalacrocoracidae, 17.7\%, fishing birds - Laridae, 10.3\%, ravens - as a large number of birds belonging to the family Ardeidae was recognized. Thus, in the spring and autumn seasons in Bukhara and adjacent waters, the migration of birds is uneven. However, changes in the species composition of ornithofauna and the time of their occurrence in water bodies often depend on whether factors and water level.

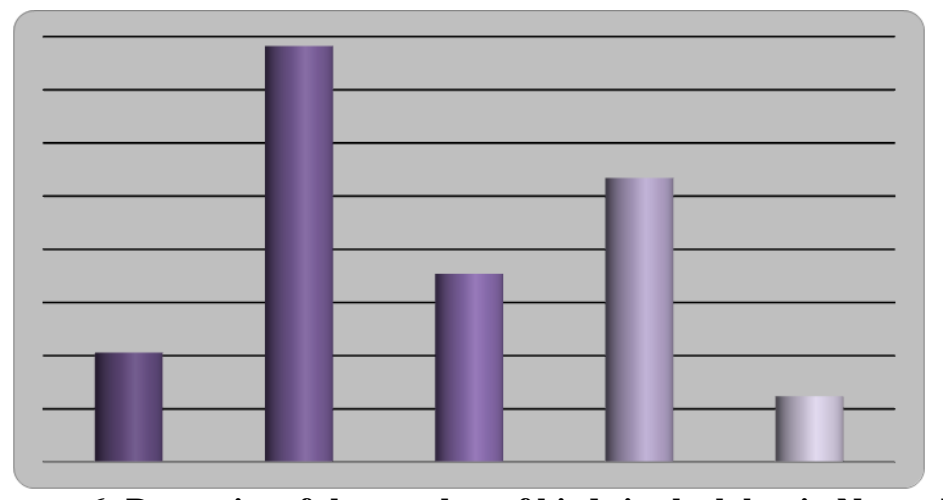

Diagram-6: Dynamics of the number of birds in the lakes in November

\section{CONCLUSION}

In summary, among the aquatic ecosystem waters, lakes are the main concentration center for aquatic liferelated species, especially for migratory species, although this composition fluctuates regularly throughout the seasons. While the main gathering centers of birds during spring and autumn migrations are observed in Dengizkul, Karakir, Ayak-Ogitma lakes, their nesting and summer concentrations are observed mainly in Khadija lake system, Zikri Karakir and Zamonbobo lakes [8.286., 10.137-147], The wintering center of the birds in the lakes is mainly observed in the Dengizkul region, partly in the Zikri and Devkhona regions. This information is of great scientific and practical importance in the organization of species conservation.

\section{REFERENCE}

1. TURAEV, M. (2012). Akpetky lakes, Sarykamysh lake, Ayakaghytma lake, and their desert surrounds: three new Important Bird Areas in Uzbekistan.

2. Novikov, G. A. (1949). Field research on the ecology of terrestrial vertebrate animals.

Citation: Turayev Mukhtor Murodovich \& Sharifova Shokhsanam Shokir qizi (2021 Seasonal Dynamics of Bird Differences and Numbers in the South-Western Kizilkum Reservoirs. South Asian Res J Bio Appl Biosci, 3(2), 31-35. 